\title{
A EFETIVIDADE DE DIREITOS FUNDAMENTAIS TRABALHISTAS DELIMITANDO A FORMA DE PAGAMENTO NO TRABALHO INTERMITENTE
}

\author{
THE EFFECTIVENESS OF FUNDAMENTAL LABOR RIGHTS BY DELIVERING THE FORM \\ OF PAYMENT FOR INTERMITTENT WORK
}

\section{Carla Teresa Martins Romar}

Bacharel em Direito pela USP. Mestre e Doutora em Direito do Trabalho pela PUC/SP. Perita em relações de trabalho - Organização Internacional do Trabalho (OIT). Professora dos cursos de Graduação, Especialização, Mestrado e Doutorado em Direito do Trabalho da PUC/SP. Vice-Coordenadora do Programa de Pós-Graduação em Direito da PUC/SP. Professora Convidada dos Cursos de Extensão em Direito do Trabalho da Università degli Studi di Roma TorVergata. E-mail: cromar@terra.com.br

\section{Leandro Cioffi}

Doutorando em Direito pela PUC/SP. Mestre em Direito pela UNESP de Franca. Professor de Direito da UFMT, Campus Universitário do Araguaia.

E-mail: leandrocioffi@bol.com.br

Recebido em: 11/07/2019

Aprovado em: 09/01/2020

\begin{abstract}
RESUMO: Estudo teórico, bibliográfico e método dedutivo que aborda o tema da forma de pagamento da contraprestação dos serviços prestados no trabalho intermitente, cujo problema consiste na questão da regra dessa forma de pagamento em face aos ditames constitucionais na perspectiva de efetividade de direitos fundamentais trabalhistas, contendo conclusão no sentido de que o trabalho intermitente sofre limites constitucionais na aplicação de suas regras dadas pela Reforma Trabalhista, especialmente para a garantia do recebimento mensal igual ou superior ao salário mínimo, da vedação de pagamento das férias e do décimo terceiro salário fragmentados juntamente com as remunerações pagas logo após a prestação de cada serviço intermitente.
\end{abstract}

Palavras-chave: Trabalho intermitente. Remuneração. Limites. Direitos fundamentais. Efetividade.

\begin{abstract}
Theoretical, bibliographic and deductive method study that addresses the theme of the form of payment of the consideration of the services provided in intermittent work, whose problem consists in the question of the rule of this form of payment in face of the constitutional dictates in the perspective of the effectiveness of fundamental labor rights, concluding that intermittent work suffers constitutional limits in the application of its rules given by the Labor Reform, especially for the guarantee of the monthly receipt equal to or above a minimum salary, the prohibition of the payment of vacation and thirteenth salary of form fragmented together with the remuneration paid immediately after the completion of each intermittent service.
\end{abstract}

Keywords: Intermittent work. Remuneration. Limits. Fundamental rights. Effectiveness. Revista de Direito Brasileira | Florianópolis, SC | v. 24 | n. 9 | p.293-310 | Set./Dez. 2019 
SUMÁRIO: Introdução. 1 Da atividade econômica e a flexibilidade do trabalho contemporâneo. $1.1 \mathrm{O}$ modo de produção em massa. 1.2 A reestruturação produtiva conforme a demanda flexível. 1.3 Consequências no mundo do trabalho (terceirização, informalização e precarização do trabalho). 2 Do contrato de trabalho intermitente como formalização do trabalho precarizado. 2.1 A abrangência generalizada de admissão do contrato de trabalho intermitente. 2.2 A relativização do requisito empregatício da continuidade. $3 \mathrm{Da}$ forma remuneratória do trabalho intermitente e a efetividade de direitos fundamentais. 3.1 O trabalho intermitente em face do princípio da norma mais favorável ao trabalhador. 3.2 A forma remuneratória do trabalho intermitente como esvaziadora de direitos fundamentais trabalhistas. 3.2.1 A garantia do salário mínimo para o trabalho com remuneração variável. 3.2.2 O sentido de pagamento em dezembro para o direito de décimo terceiro salário. 3.2.3 O sentido de direito de fruição remunerada das férias. Conclusão. Referências.

\section{INTRODUÇÃO}

O presente estudo aborda os contornos dados pela Reforma Trabalhista, instituída Lei n. 13.467/2017, acerca da forma de pagamento da contraprestação dos serviços prestados no trabalho intermitente, tratando especificamente da abordagem de suas regras em face da efetividade de direitos fundamentais em questão. Trata-se de um estudo teórico e bibliográfico, com metodologia dedutiva.

A justificativa da temática do presente estudo parte da constatação de que a Reforma Trabalhista, ao instituir a modalidade contratual do trabalho intermitente no ordenamento jurídico, estabeleceu a forma de pagamento da contraprestação de serviços ao trabalhador de maneira fragmentada, a saber, paga-se logo após o término de cada prestação de serviço anteriormente convocada e aceita. Além da remuneração paga de maneira fracionada na medida de sua prestação de serviços, o trabalhador intermitente receberá cumulativamente já os valores proporcionais ao período trabalhado, correspondentes às férias devidas, ao décimo terceiro salário, ao repouso semanal remunerado e aos adicionais legais. Com efeito, ao longo das prestações de serviços, o trabalhador intermitente receberá de maneira adiantada valores em montantes inexpressivos de tais parcelas ao invés de recebê-las no acúmulo devido na época a ela determinada, por exemplo, as férias no momento da concessão de sua fruição. Ademais, a característica de descontinuidade do trabalho intermitente importa em sujeição do trabalhador possivelmente a grandes períodos de inatividade e insuficientes de atividade para acumular montantes remuneratórios compatíveis em comparação a de um emprego permanente. Diante dessas justificativas constatadas, a problemática suscitada no presente estudo consiste no questionamento se essa forma de pagamento da contraprestação do trabalho intermitente está ou não contrariando determinados direitos fundamentais trabalhistas e se a efetividade desses direitos está sendo prejudicada pelo regramento instituído pela Reforma Trabalhista para essa modalidade de contratação.

O objetivo do presente estudo consiste na verificação dos sentidos interpretativos de determinados direitos fundamentais envolvidos na problemática supracitada e examinando-os em face de regras específicas da Reforma Trabalhista referentes ao contrato de trabalho intermitente. Para tanto, tem-se como objetivos específicos compreender a dinâmica básica da atividade econômica contemporânea e o consequente modo organizacional do trabalho e suas consequências, bem como compreender a sistemática básica da regulamentação do contrato de trabalho intermitente dada pela Reforma Trabalhista, englobando o critério de abrangência para a sua admissibilidade, a consequência da descontinuidade como elemento de sua caracterização jurídica, bem como as limitações constitucionais, envolvidas na forma de pagamento da contraprestação do trabalho intermitente, especialmente no tocante à efetividade de direitos fundamentais envolvidos. 


\section{DA ATIVIDADE ECONÔMICA E A FLEXIBILIDADE DO TRABALHO CONTEMPORÂNEO}

\subsection{0 modo de produção em massa}

Entre o final do século XIX e meados do século XX, na atividade industrial, dois modos de produção foram determinantes para a organização do trabalho: o taylorismo e o fordismo.

No taylorismo, a ideia básica da organização do trabalho consiste na separação entre a concepção e a execução do trabalho. A concepção do trabalho desenvolvida (planejada, instituída a "tarefa") pela direção da empresa, e ao trabalhador apenas a execução dessa tarefa, não lhe permitindo mais administrar a concepção do seu trabalho. Segundo Taylor (1995, p. 34), “[...] quase todos os atos dos trabalhadores devem ser precedidos de atividades preparatórias da direção, que habilitam os operários a fazerem seu trabalho mais rápido e melhor do que em qualquer outro caso. [...]." Além disso, afirma que "[n]a tarefa é especificado o que deve ser feito e também como fazê-lo, além do tempo exato concebido para a execução. [...].” (TAYLOR, 1995, p. 42)

Por essas afirmações, nota-se uma compreensão da separação entre a concepção e a execução do trabalho como sentido de implementação hábil para racionalizar o trabalho e com isso potencializar a produção.

Mais adiante, já com o fordismo, o emprego do taylorismo foi intensificado na busca pela massificação da produção. Nesse contexto de inovação produtiva englobam-se iniciativas de "estandardização", de produção em "larga escala", impulsionadas por uma linha de produção ${ }^{3}$.

Além disso, na organização do trabalho, o fordismo teve como característica diferencial o trabalho especializado (funções extremamente divididas e com movimentos corporais estritamente limitados ao que for necessário para o trabalhador executar a sua tarefa). Segundo Ford (1954, p. 91) "[n]ossa organização é tão especializada, e tão intimamente se relacionam as partes, que nem por um momento poderíamos deixar ao operário liberdade de ação. [...]." Além disso, o espaço de movimentação corporal do trabalhador é limitado também pela grande quantidade de máquinas ao seu redor envolvidas na operação, pois segundo sua afirmação :

[...] Um visitante terá a impressão de que se acham montadas umas sôbre [sic] as outras e no entanto estão cientìficamente [sic] dispostas, não só quanto à sequiência [sic] das operações, mas ainda no dar a cada operário e a cada máquina o espaço exato de que precisem, nem uma polegada mais, nem uma polegada menos. [...]. (FORD, 1954, p. 93)

Segundo Thomas Gounet (1999, p. 18-19), são cinco as principais transformações em que se apoia o fordismo: a produção em massa para atender a um amplo consumo; a racionalização das tarefas parcelando-as; a criação da linha de produção (esteira rolante), regulando a ligação entre os diferentes trabalhos e a cadência do trabalho controlável pela empresa; a padronização de peças para a redução do trabalho a simples gestos e redução de desperdícios de adaptação; e a automatização das fábricas.

\footnotetext{
${ }^{1}$ A respeito da "estandardização", Ford a comenta no sentido de que ela corresponde em "[...] dedicar dias e noites, às vêzes [sic] anos, primeiro ao estudo de um artigo que corresponda do modo mais perfeito aos desejos e necessidades do público, e depois à melhor maneira de fabricá-lo. [...].” (FORD, 1954, p. 48)

${ }^{2}$ Sobre a produção em série, em larga escala, Ford demonstra o seu pensamento dando a compreender como um modo mais eficiente na gestão da produtividade da indústria, tanto que, em suas palavras, "[é] claro que, fazendo-se a mesma coisa pela segunda vez sai ela sempre melhor. Ignoro como esta verdade não penetrava na indústria da época, a não ser que os fabricantes tivessem muita pressa em pôr à venda um artigo[...].” (FORD, 1954, p. 47)

${ }^{3} \mathrm{~A}$ respeito da produção em linha, explica Ford que um dos princípios correspondentes à montagem é o de "[u]sar uma rêde [sic] de deslisadeiras [sic] por meio das quais as peças a montar se distribuam a distâncias convenientes." (FORD, 1954, p. 70)
} 
No âmbito do Direito do Trabalho, sobretudo na primeira metade do século XX, o modo de produção capitalista com um padrão organizacional do trabalho especializado (tarefas reduzidas a pequenos gestos repetitivos e com negações intelectuais diversas dos operários) foi uma realidade que serviu de base para a regulação das condições de trabalho, surgindo diversos direitos que conferem com essa realidade originária, tais como a limitação da jornada de trabalho, as regras de higiene, saúde e segurança do trabalho, a concessão de um período de descanso mais prolongado, correspondente às férias, regramento do trabalho noturno, instituição de regras de proteção ao trabalho da mulher, etc. Porém, a partir da segunda metade do século XX, esse cenário da produção capitalista passou por significativas mudanças, alterando o seu modo de produção massificado para modos flexíveis e, consequentemente os modos organizacionais do trabalho para também flexíveis.

\subsection{A reestruturação produtiva conforme a demanda flexível}

A partir de meados da década de 1970, como reação às crises econômicas durante as quais as empresas passaram a enfrentar um cenário de baixo crescimento econômico (ou até mesmo de recessão), iniciou-se um processo de nova estruturação produtiva com o seu modo flexível de atuação, buscando acompanhar proporcionalmente às demandas do mercado, estabelecendo-se uma nova racionalização produtiva, mais variável conforme as demandas e o crescimento econômico.

Como explica Geraldo Augusto Pinto (2016, p. 44-45), constatou-se uma instabilidade macroeconômica num cenário contendo um alto desequilíbrio das contas externas, aumento no preço do petróleo, o dólar sendo valorizado e desvalorizado sucessivamente, instabilidade esta por sua vez resultando numa redução de investimentos da produção industrial, inclusive já com um cenário de crescimento econômico no setor de serviços, redirecionando as estratégias industriais para atender, dentre outros, a objetivos de produção flexível, maior qualidade dos produtos, redução de seus preços, rapidez e precisão nas suas entregas aos clientes, fazendo surgir interesses por experimentar alternativas diversas ao do taylorismo/fordismo na produção industrial e na organização do trabalho.

A esse respeito, no que David Harvey denomina de "acumulação flexível”, ela "[...] é marcada por um confronto direto com a rigidez do fordismo. Ela se apoia na flexibilidade dos processos de trabalho, dos mercados de trabalho, dos produtos e padrões de consumo. [...]." (HARVEY, 2014, p. 140)

Dentre os sistemas de produção flexível, o que teve maior difusão foi o toyotismo, modelo japonês desenvolvido na empresa Toyota. Na análise desse sistema de produção, Benjamin Coriat emprega a denominação de "fábrica mínima", que "[...] deverá necessariamente também ser uma fábrica "flexível", capaz de absorver com um efetivo reduzido as flutuações quantitativas ou qualitativas da demanda. [...]." (CORIAT, 1994, p. 34)

Fazendo destaque a importantes características do então Sistema Toyota de Produção,

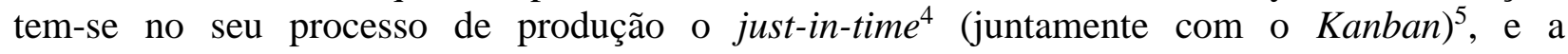

\footnotetext{
${ }^{4}$ Basicamente, just-in-time no processo produtivo quer dizer que "[...] as partes corretas necessárias à montagem alcançam a linha de montagem no momento em que são necessários e somente na quantidade necessária. [...]” (OHNO, 2015, p. 3).

${ }^{5}$ Para a efetiva execução do just-in-time é necessário que o processo produtivo possua uma alta sincronia entre os diversos setores e etapas da produção. E essa sincronia foi possível no Sistema Toyota por meio de uma dinâmica sistematizada, denominada de Kanban, que consiste em um "[...] meio usado para transmitir informação sobre apanhar ou receber a ordem de produção[...]" (OHNO, 2015, p. 5).
}

Revista de Direito Brasileira | Florianópolis, SC | v. 24 | n. 9 | p.293-310 | Set./Dez. 2019 
"autonomação"6 (também com o gerenciamento pela visão) ${ }^{7}$, características que por sua vez demonstram a efetiva flexibilidade nesse sistema de produção e, por conseguinte, a tomada da força de trabalho.

A reestruturação produtiva, sobretudo tendo o toyotismo como o seu predominante modo de produção, desencadeou grandes modificações organizacionais do trabalho, expandindo-as tanto nas indústrias em geral quanto também na adaptação de suas estruturas em diversos setores da atividade econômica, e até mesmo na administração pública ${ }^{8}$. Com efeito, geraram-se expressivas e impactantes alterações no padrão estrutural do trabalho, entre as quais destacam-se os fenômenos da terceirização, da precarização e da informalização do trabalho, conforme abordagens seguintes.

\subsection{Consequências no mundo do trabalho (terceirização, informalização e precarização do trabalho)}

Como visto anteriormente, diversos foram os impactos da reestruturação produtiva.

Ricardo Antunes (2018, p. 55-56) fala sobre a ocorrência de um processo de "precarização estrutural do trabalho", tendência esta que já se desenhava no início da década de 1970 nos processos de reestruturação produtiva. Esse fenômeno de precarização do trabalho determina uma modificação nas formas de tomada da força de trabalho humana, e assim indo além do mero impacto quantitativo no desemprego. Assim, segundo explica Robert Castel (2012, p. 514, grifo do autor):

[...] o desemprego é apenas a manifestação mais visível de uma transformação profunda da conjuntura do emprego. A precarização do trabalho constitui-lhe uma outra característica, menos espetacular porém ainda mais importante, sem dúvida. O contrato de trabalho por tempo indeterminado está em via de perder sua hegemonia. [...].

Nota-se a precarização do trabalho como um estado de ampla instabilidade ocupacional e de renda do trabalhador, tornando-o vulnerável às oscilações de demanda flexível da empresa na tomada de força de trabalho humana, impulsionando, inclusive, à flexibilidade dos direitos e condições de trabalho.

Nessa realidade, a informalidade e a terceirização se constituem como formas intimamente ligadas à precarização do trabalho. Nesse sentido, a respeito da informalidade, segundo Ricardo Antunes e Graça Druck (2015, p. 24-25), ela “[...] não é sinônimo de precariedade, mas a sua vigência expressa formas de trabalho desprovido de direitos e, por isso, encontra clara sintonia com a precarização. [...]." A respeito da terceirização, afirmam também que "[...] nas últimas décadas do século XX e início do XXI, estamos defronte de novas modalidades e modos de ser da precarização, da qual a terceirização tem sido um de seus elementos mais decisivos." (ANTUNES; DRUCK, 2015, p. 25)

Em comparação aos empregados diretos da mesma empresa, os terceirizados se encontram mais sujeitos à precarização do trabalho. Nesse sentido, os trabalhadores terceirizados, segundo Antunes e Druck (2015, p. 27), são os mais vulneráveis - que recebem menor remuneração, os que

\footnotetext{
${ }^{6}$ Tem-se como o significado da autonomação o de "[...] transferência de inteligência humana para uma máquina. [...]." (OHNO, 2015, p. 108). Porém, explica que esse conceito de autonomação "[...] é aplicado não somente à maquinaria como também à linha de produção e aos operários. [...].” (OHNO, 2015, p. 108).

${ }^{7}$ A respeito do gerenciamento pela visão, segundo explica Ohno (2015, p. 109), "[e]m termos de qualidade, quaisquer produtos com defeitos são obrigados a aparecer, porque o progresso real do trabalho comparado aos planos de produção diária é sempre tornado visível. [...]."

8 "Os protocolos organizacionais do toyotismo, muitos deles traduzidos em valores e regras de gestão do trabalho vivo, dos mais diversos tipos, atingem os empreendimentos capitalistas, seja na área da indústria, seja na área de serviços (inclusive na administração pública). [...].” (ALVES, 2007, p. 157)
} 
mais trabalham, os que possuem maior instabilidade e menos direitos, e os que mais se acidentam e morrem, como decorrência de maior precariedade das condições de trabalho.

Também correlacionada à precarização, a informalização, segundo Ricardo Antunes (2013, p. 15), vem se demonstrando expressivamente ampliada com a submissão dos trabalhadores a contratos temporários sucessiva e instavelmente, para trabalharem dentro ou fora da empresa e sem anotação em carteira de trabalho.

Trata-se de uma realidade que conduz, segundo a Organização Internacional do Trabalho (OIT), a "formas atípicas de emprego", que incluem, entre outros, o trabalho temporário, o trabalho a tempo parcial e o trabalho intermitente (ORGANIZACIÓN INTERNACIONAL DEL TRABAJO, 2016, p. 1-2).

No Brasil, gradativamente o legislador foi absorvendo algumas dessas formas atípicas de emprego, tendo iniciado com a regulamentação do trabalho temporário (Lei n. 6.019/74), passando pelo trabalho a tempo parcial (Medida Provisória 2.164-41/2001) e agora, com a Reforma Trabalhista, a previsão do contrato de trabalho intermitente. Com este último, segundo o legislador, a informalidade no trabalho pode ser atenuada, já que essa modalidade de contratação leva à formalização do vínculo contratual de trabalho de diversos trabalhadores que, até então, estavam ao desamparo da lei.

Segundo a OIT, a preocupação com o crescimento das "formas atípicas de emprego" reside no fato de que, comparadas com o "emprego típico" (fundado no contrato de trabalho por tempo indeterminado e com todas as garantias legais), estas modalidades estão associadas com uma maior insegurança para os trabalhadores e com a precarização de direitos. Nesse sentido, destaque-se que "[1] a Organización Internacional del Trabajo (OIT) reconoce que el trabajo puede revestir formas contractuales variadas. [...]." (ORGANIZACIÓN INTERNACIONAL DEL TRABAJO, 2016, p. 2) Mesmo porque, segundo essa mesma entidade internacional, reconhece-se que o mundo do trabalho não é estático (sendo flexível, portanto) o que necessita constantemente da atuação política e legislativa a fim de assegurar a efetividade do trabalho decente:

[...] el mundo del trabajo no es estático y presenta desafíos que necesitan respuestas de política. Por ello, es preciso realizar un esfuerzo constante para adecuar la reglamentación y las políticas con el fin de garantizar el trabajo decente para todos. Por otra parte, hay que desplegar mayores esfuerzos para asegurar que la normativa se aplique efectivamente. [...]. (ORGANIZACIÓN INTERNACIONAL DEL TRABAJO, 2016, p. 22)

Especificamente em relação ao trabalho intermitente, objeto do presente estudo, ainda que louvável a intenção do legislador brasileiro em formalizar a contratação de um grande contingente de mão-de-obra até então mantido à margem da proteção, o fato é que, apesar de formais, os trabalhadores admitidos como intermitentes não alcançam qualitativamente o patamar equivalente dos empregos com jornadas de trabalho fixas, principalmente pelo sistema de pagamento da remuneração e de seus componentes, conforme abordagens nos itens seguintes.

\section{DO CONTRATO DE TRABALHO INTERMITENTE COMO FORMALIZAÇÃO DO TRABALHO PRECARIZADO}

\subsection{A abrangência generalizada de admissão do contrato de trabalho intermitente}

Segundo Castel (2012, p. 516) "[a] diversidade e a descontinuidade das formas de emprego estão em via de suplantar o paradigma do emprego homogêneo e estável."

O padrão flexível da tomada da força de trabalho humana torna-se institucionalizado por meio da regulamentação do contrato de trabalho intermitente, principalmente se essa for admissível generalizadamente para quaisquer profissões e atividades empresariais. 
É possível que legislações, segundo o sistema de cada país, adotem critérios distintos variando-os quanto à abrangência das espécies de profissões e atividades empresárias admissíveis de contratar trabalho intermitente. Como um exemplo de critério de abrangência mais limitada, tem-se o sistema português, sendo que o artigo $157^{\circ}$ do Código do Trabalho (Lei n. ${ }^{\circ} 11$ de 2009) possibilita a contratação de trabalho intermitente apenas nos casos de intermitência como atividade da empresa, vedando-os para contratos com termo resolutivo ou por prazo determinado, conforme o seguinte teor normativo:

\section{Admissibilidade de trabalho intermitente}

1 - Em empresa que exerça actividade com descontinuidade ou intensidade variável, as partes podem acordar que a prestação de trabalho seja intercalada por um ou mais períodos de inactividade.

2 - O contrato de trabalho intermitente não pode ser celebrado a termo resolutivo ou em regime de trabalho temporário. (PORTUGAL, 2009, online, grifo do autor)

Já no Brasil, a Reforma Trabalhista demonstra um critério generalizado para admissão de trabalho intermitente, pois, na sua definição legal, o $\S 3^{\circ}$ do artigo 443 da CLT reformada enfatiza a sua possiblidade "[...] independentemente do tipo de atividade do empregado e do empregador, exceto para os aeronautas, regidos por legislação própria. (Incluído pela Lei $\mathrm{n}^{\circ}$ 13.467, de 2017)" (BRASIL, 1943, online).

Ademais, a extrema flexibilidade do trabalho intermitente dada pela Reforma Trabalhista se caracteriza por um peculiar elemento de sua definição legal que confere uma extrema prerrogativa do empregador de contratações de trabalho nessa modalidade, que é o elemento da descontinuidade. Elemento esse que, por força do $\S 3^{\circ}$ do artigo 443 da CLT reformada, possa-se acumular inatividade e atividade do trabalhador em lapsos temporais de horas, dias e até meses.

\subsection{A relativização do requisito empregatício da continuidade}

O trabalho não eventual, para Carla Teresa Martins Romar (2017, p. 111), “[...] significa dizer que o empregado se obriga a prestar serviços com continuidade, [...]", observando ainda que “[o] que caracteriza a habitualidade não é a prestação diária de trabalho, mas, sim, o sentido de permanência e de prolongamento no tempo que a prestação dos serviços tem." (ROMAR, 2017, p. 111). Explica ainda que, destacando dentre as teorias envolvidas sobre esse tema da habitualidade, para a prática de caracterização da relação de emprego, o legislador não havia adotado a "teoria da descontinuidade" (que, para a relação de emprego, sustenta a ininterrupção e continuidade da prestação de serviços do trabalhador a um mesmo tomador), mas talvez como a de maior prestígio doutrinário a "teoria dos fins do empreendimento" (que, para a relação de emprego, sustenta a habitualidade da prestação de serviços do trabalhador dada pelas atividades finalísticas da empresa). (ROMAR, 2017, p. 112-113)

Ainda a respeito da "teoria dos fins do empreendimento", segundo Mauricio Godinho Delgado (2013, p. 287), “[i]nforma tal teorização que eventual será o trabalhador chamado a realizar tarefa não inserida nos fins normais da empresa - tarefas que, por essa mesma razão, serão esporádicas e de estreita duração. [...]."

Contudo, a Reforma Trabalhista, ao regulamentar o trabalho intermitente, relativizou o requisito empregatício geral da continuidade (ou habitualidade), pois, pelo teor $\S 3^{\circ}$ do artigo 443 da CLT reformada, o legislador desconsiderou tanto a finalidade do empreendimento do empregador quanto a continuidade de prestação de serviços do trabalhador. Com efeito, a descontinuidade se coloca como elemento legitimador de inatividade do trabalhador, desobrigando a empresa de qualquer ônus durante o período em que o mesmo permanece inativo.

Ocorre que, por essa relativização da continuidade, surge a seguinte questão problemática: a existência de continuidade no plano da realidade fática descaracteriza o contrato de trabalho 
intermitente convertendo-o em contrato de trabalho por prazo indeterminado?

Ao tratar da limitação de se utilizar o contrato de trabalho intermitente, em sua tese de doutorado, Maria Ivone Fortunato Laraia (2018, p. 160) afirma que a interpretação mais adequada para esta modalidade de contrato de trabalho é a da sua utilização em caso de verificada intermitência (por "descontinuidade" ou por "intensidade variável") pela natureza da atividade do empregador, e também excluindo sua utilização para atividades "regidas por legislação própria". Entretanto, o emprego de tal entendimento torna-se obstaculizado pela própria disposição do $\S 3^{\circ}$ do artigo 442 da CLT reformada, que estabelece expressamente tanto a descontinuidade quanto a independência de atividade da empresa ou do trabalhador, sendo os profissionais aeronautas como a única vedação expressa para a contratação de trabalho intermitente.

Nota-se, ainda, que o $\S 3^{\circ}$ do artigo 443 da CLT reformada não estabelece a descontinuidade como rigoroso requisito de validade do contrato de trabalho intermitente. Pelo contrário, por essa norma, a descontinuidade pode ser tanto ampla (em meses) quanto ínfima (em horas). Daí, por essa regra, é possível uma descontinuidade tão irrisória de tempo a ponto de o trabalho intermitente ser praticamente contínuo por realidade fática.

Um exemplo a respeito dessa situação seria o de uma formal contratação de trabalho intermitente onde ocorressem consecutivas convocações/prestações semanais de trabalho que, somadas, atingem o montante de 44 horas prestadas ao longo de uma semana, e essas consecutivas convocações/prestações se prolongam por mais de um ano. Desde já, essa estratégia apresenta duas vantagens patronais (e consequentes grandes prejuízos para a condição social do trabalhador): o parcelamento (fragmentado) de parte sua folha de pagamento entre férias, décimo terceiro salário; e a prerrogativa de descontinuidade quando bem entender (o que é vedado para os empregados com prazo determinado). Diante da expressa definição legal constante do $\S 3^{\circ}$ do artigo 443 da CLT reformada não nos parece que situações como essa possam levar ao entendimento de que a contratação se transformaria em por tempo indeterminado, mantendo-se a incidência do regramento do trabalho intermitente mesmo nessas hipóteses. Ou seja, a partir da definição legal constata-se que o período de intermitência insere-se no poder de direção do empregador, que pode utilizar-se dessa modalidade de contratação como forma de redução de custos, como ressaltado acima.

Nota-se, ainda, que o único requisito real de validade do contrato de trabalho intermite é o da forma escrita (artigo 452-A), dando a entender que somente no caso de trabalho intermitente com vício de forma ocorrerá o risco de a geração do vínculo empregatício por tempo indeterminado, caso a realidade fática enquadrar-se nos artigos $3^{\circ}$ e $9^{\circ}$ da CLT. Portanto, a precarização do trabalho (manifestada pela instabilidade de renda e de prestação de serviços) pode ser muito maior do que aparentemente demonstra.

\section{DA FORMA REMUNERATÓRIA DO TRABALHO INTERMITENTE E A EFETIVIDADE DE DIREITOS FUNDAMENTAIS}

A despeito de críticas que possam ser feitas à forma de regulamentação pelo legislador pátrio do trabalho intermitente, o objeto do presente estudo diz respeito especificamente à análise da forma remuneratória do trabalho intermitente frente à necessária efetividade que se deve conferir aos direitos fundamentais. O questionamento que se coloca é se o pagamento fragmentado da remuneração pelo trabalho intermitente prestado e dos direitos trabalhistas assegurados (especificamente férias e décimo terceiro salário) é compatível com a efetividade dos direitos fundamentais dos trabalhadores.

Pelo esquema classificatório de José Afonso da Silva (2015, p. 81-82) acerca da eficácia 
e aplicabilidade das normas constitucionais (a saber, as de "eficácia plena", "eficácia contida"10 e "eficácia limitada"11) - apesar de sua notória importância na utilização e operacionalidade jurídica -, diversas normas de direitos fundamentais trabalhistas podem ser compreendidas como de eficácia plena, porém, na prática, dotadas de imensa dificuldade de concretização sem uma regulamentação infraconstitucional.

Portanto, para o presente estudo, a interpretação e a análise de efetividade dos parâmetros constitucionais formulados segue a linha de entendimento de que tais normas são possíveis de sofrer restrições e regulamentações pelo legislador infraconstitucional, desde que conforme ao que for devido para a satisfatória e possível concretização (efetividade, realização) do correspondente direito fundamental ${ }^{12} \mathrm{e}$ em harmonia com demais direitos colidentes no sistema constitucional. ${ }^{13}$

Ressalta-se, ainda, o entendimento de que essas restrições a direitos fundamentais por meio de legislação infraconstitucional, segundo afirma Ingo Wolfgang Sarlet (2012, p. 404) “[...] somente serão tidas como justificadas se guardarem compatibilidade formal e material com a Constituição. [...]".

Assim, nos subitens seguintes a abordagem contempla o exame de regras referentes ao pagamento da contraprestação do trabalho intermitente ora dadas pela Reforma Trabalhista em face de conjunto de normas constitucionais relacionadas à compreensão de direitos fundamentais envolvidos, e com isso verificando compreensões de efetividade ou não dos mesmos e de compatibilidade ou incompatibilidade constitucional das referidas regras infraconstitucionais.

\subsection{O trabalho intermitente em face do princípio da norma mais favorável ao trabalhador}

Enquanto função interpretativa, o princípio da proteção ao trabalhador faz com que o foco central do Direito do Trabalho seja, segundo Américo Plá Rodriguez (2002, p. 83), o “[...] de proteger uma das partes com o objetivo de, mediante essa proteção, alcançar-se uma igualdade substancial e verdadeira entre as partes." Segundo o seu entendimento, um dos modos através do qual tal princípio se expressa, por conseguinte, é por um critério que ele denomina por "in dubio, pro operário" o qual "[...] deve utilizar o juiz ou o intérprete para escolher, entre vários sentidos possíveis de uma norma, aquele que seja mais favorável ao trabalhador[...]" (RODRIGUEZ, 2002, p. 107), sentido este, porém, entendido por Delgado (2010, p. 113) como sendo apenas uma dimensão interpretativa do princípio da norma mais favorável.

Segundo Delgado (2010, p. 61-62) o princípio da norma mais favorável é claramente assumido pela Constituição, afirmando-se no caput de seu artigo $7^{\circ} \mathrm{o}$ seu preceito normativo regulatório mais notável, já que o teor redacional deste dispositivo estabelece como direito dos trabalhadores - além dos já arrolados em seus incisos - " [...] outros que visem à melhoria de sua

\footnotetext{
${ }^{9}$ Normas constitucionais classificadas como “de eficácia plena” são, segundo José Afonso da Silva (2015, p. 81-82) "[...] todas as normas que, desde a entrada em vigor da constituição, produzem todos os seus efeitos essenciais (ou têm a possiblidade de produzi-los), todos os objetivos visados pelo legislador constituinte[...]."

${ }^{10}$ São normas constitucionais classificadas como "de eficácia contida" aquelas que sua aplicabilidade, segundo José Afonso da Silva (2015, p. 114), “[...] não fica condicionada a uma normação [sic] ulterior, mas fica dependente dos limites (daí: eficácia contida) que ulteriormente se lhe estabeleçam mediante lei, ou de que as circunstâncias restritivas, constitucionalmente admitidas, ocorram [...]."

${ }^{11}$ Normas constitucionais classificadas como "de eficácia limitada”, segundo José Afonso da Silva (2015, p. 82) “[...] são todas as que não produzem, com a simples entrada em vigor, todos os seus efeitos essenciais[...]."

${ }^{12}$ De acordo com Virgílio Afonso da Silva $(2011$, p. 246) “[...] todos os direitos fundamentais são restringíveis e todos os direitos fundamentais são regulamentáveis. [...]” Além disso, explica que essa possibilidade de restringir tais direitos "[...] impõe sérios ônus de fundamentação ao legislador e será sempre submetida ao controle da proporcionalidade. [...]" (SILVA, V. A., 2011, p. 249).

${ }^{13}$ A propósito da referida harmonização, confere-se - como recurso doutrinário de apoio interpretativo da Constituição - com o "princípio da concordância prática", o qual, na explicação de Bulos (2018, p. 460) "[...] tem como meta coordenar, harmonizar e combinar bens constitucionais conflitantes, evitando o sacrifício total de uns em relação aos outros."
} 
condição social[...]" (BRASIL, 1988, online).

Além de sua função interpretativa, os princípios também devem compreendidos como espécies de normas, sendo, segundo Robert Alexy (2017, p. 90), "mandamentos de otimização" (mandamento no sentido tanto de permitir quanto de proibir), explicando ainda que, por essa qualidade, os princípios "[...] são caracterizados por poderem ser satisfeitos em graus variados e pelo fato de que a medida devida de sua satisfação não depende somente das possibilidades fáticas, mas também das possibilidades jurídicas. [...].” (ALEXY, 2017, p. 90)

Assim, compreende-se que a ressalva constitucional de melhoria da condição social dos trabalhadores expressa no caput do artigo $7^{\circ}$ da Constituição é um princípio de direito fundamental que, além de orientar a interpretação e a aplicação de normas polissêmicas de Direito Trabalhista para o sentido mais favorável ao trabalhador, também impõe normativamente o legislador infraconstitucional a uma limitação de restringir direitos fundamentais trabalhistas sem justificativa constitucional e assim de modo a agravar a condição social dos trabalhadores.

O exame de compatibilidade constitucional ou incompatibilidade constitucional de legislações trabalhistas em face do princípio da norma mais favorável ao trabalhador não se baseia isolada e unicamente no preceito do caput do artigo $7^{\circ}$ da Constituição, e sim um conjunto de normas a ele agregado, compondo um "parâmetro" ou "bloco de constitucionalidade"14.

Assim, destacando algumas normas indissociáveis à interpretação do caput do artigo $7^{\circ}$ da Constituição, tem-se a dos princípios fundamentais da dignidade da pessoa humana (art. $1^{\circ}$, inciso III), do valor social do trabalho (artigo $1^{\circ}$, inciso IV), a do trabalho como direito social (artigo $6^{\circ}$ ), e a da valorização do trabalho humano como fundamento da ordem econômica (artigo 170, caput).

Com a qualificação de princípio fundamental do valor social do trabalho, explica Cláudio Mascarenhas Brandão (2018, p. 131) que se “[...] fincou de modo definitivo a opção política de estabelecer tratamento privilegiado ao trabalho como elemento integrante do próprio conceito de dignidade humana e fundamentador do desenvolvimento da atividade econômica. [...]." Assim, pode-se compreender que o valor social do trabalho serve peculiarmente para a dignificação humana do trabalhador.

Sobre o conteúdo do princípio do valor social do trabalho, explica que, "[a]o analisá-lo, o intérprete deve voltar-se aos valores abraçados no contexto social do qual foram originados a fim de torná-los efetivos." (BRANDÃO, 2018, p. 131) E no contexto da concretização desse princípio fundamental, explica também que "[...] devem ser evitadas interpretações que traduzam o enfraquecimento da valorização do trabalho. [...].” (BRANDÃO, 2018, p. 133)

Sobre os fundamentos da ordem econômica estabelecidos no artigo 170 da Constituição, nas palavras de Eros Roberto Grau (2018, p. 1883), “[...] qualquer prática econômica (mundo do ser) incompatível com a valorização do trabalho humano e com a livre-iniciativa, ou que conflite com a existência digna de todos, conforme os ditames da justiça social, será adversa à ordem constitucional. [...].” Explica também que na Constituição há uma interação entre o princípio do valor social do trabalho (artigo $1^{\circ}$, inciso IV) com o fundamento de valorização do trabalho humano na ordem econômica (artigo 170, caput), interação que importa em dar ao trabalho e aos trabalhadores um "tratamento peculiar" na medida em que o trabalho passa a receber uma proteção "politicamente racional". (GRAU, 2018, p. 1883)

\footnotetext{
${ }^{14}$ A concepção de "parâmetro constitucional" (ou "bloco de constitucionalidade"), segundo explica Bulos (2018, p. 179, grifo do autor), "[...] parte do pressuposto de que as constituições formam blocos monolíticos e harmônicos, coordenando feixes de normas e princípios explícitos e implícitos, dotados de cogência [sic] (força normativa), não podendo ser separados para fins de controle de constitucionalidade."
} 


\subsection{A forma remuneratória do trabalho intermitente como esvaziadora de direitos fundamentais trabalhistas}

A forma remuneratória a que se refere o presente estudo é a da fragmentação dos pagamentos dos direitos arrolados no $\S 6^{\circ}$ do artigo 452-A, da CLT reformada, em especial da remuneração, das férias e do décimo terceiro salário, excetuando dessa análise o pagamento do repouso semanal remunerado (inciso IV) e dos adicionais legais (inciso V), já que para tais direitos a remuneração (inciso I) é a matéria determinante de seus pagamentos, tornando a discussão essencialmente a mesma.

Diversos direitos fundamentais trabalhistas foram originariamente instituídos por regulamentações infraconstitucionais. Daí ser compreensível que, em uma interpretação constitucional dirigida a tais direitos, seus conceitos básicos possam ser apoiados do que já consta previamente desenvolvido em normas infraconstitucionais regulamentadoras dos mesmos (por exemplo, compreender o sentido do direito fundamental do repouso semanal remunerado apoiando-se às regras da Lei 605/1949), técnica esta que servirá de apoio nas compreensões dos direitos especificados nos subitens seguintes. Entretanto, esta técnica requer cautela do intérprete para que não se incorra em uma equivocada interpretação constitucional legitimadora de contrariedade constitucional. Nesse sentido, referindo-se ao exercício desse procedimento de interpretação da Constituição conforme a lei, segundo ensina Paulo Gustavo Gonet Branco (2019, p. 96), "[a] admissibilidade sem a devida prudência de um tal exercício poderia levar à coonestação de inconstitucionalidades, deturpando-se o legítimo sentido da norma constitucional. [...]."

\subsubsection{A garantia do salário mínimo para o trabalho com remuneração variável}

Da maneira como foi inserido o contrato de trabalho intermitente pela Reforma Trabalhista, segundo Mauricio Godinho Delgado e Gabriela Neves Delgado (2017, p. 154-155), se suas regras forem lidas em sua literalidade, tal modalidade buscaria romper dois direitos e garantias dentre os estruturalmente centrais do Direito do Trabalho, que são as noções de duração do trabalho (que passa a não dar efeitos jurídicos ao real tempo de disposição do trabalhador ao empregador) e de salário (pretendendo desestruturar sua noção ao possibilitar o seu pagamento tanto por unidade de tempo, quanto por unidade de obra ou misto de ambos), ou seja, o que chamam, caso haja uma interpretação estritamente literal, de criação de "[...] um contrato de trabalho sem salário. Ou melhor: o salário poderá existir, ocasionalmente, se e quando o trabalhador for convocado para o trabalho[...]." (DELGADO; DELGADO, 2017, p. 155, grifo dos autores)

Por outro lado, já se baseando numa interpretação lógica, racional, sistemática e teleológica, Mauricio Godinho Delgado e Gabriela Neves Delgado entendem que a Reforma Trabalhista, ao regulamentar o contrato de trabalho intermitente, está estabelecendo, no tocante ao salário, outra modalidade de salário por unidade de obra (ou por tarefa pelo menos) - já que o seu cálculo se dá considerando a produção do trabalhador no cômputo de horas em que ele se coloca à efetiva disposição e no ambiente de trabalho do empregador - o que, por conseguinte, confere ao trabalhador a percepção de no mínimo um salário mínimo mensal, sob fundamento da garantia do salário não inferior ao mínimo por se tratar de trabalhadores com percepção de remuneração variável, nos termos do artigo 78, caput e parágrafo único da CLT e do inciso VII do artigo $7^{\circ}$ da Constituição. (DELGAGO; DELGADO, 2017, p. 155)

O inciso VII do artigo $7^{\circ}$ da Constituição garante aos trabalhadores urbanos e rurais a "[...] garantia de salário, nunca inferior ao mínimo, para os que percebem remuneração variável[...]" (BRASIL, 1988, online). Trata-se de uma norma na qualidade de garantia ${ }^{15}$, ou seja, que assegura

\footnotetext{
${ }^{15}$ Ao tratar da distinção entre "direitos" e "garantias" entre as normas constitucionais, Rui Barbosa (1978, p. 124) afirma que as disposições de direitos são entendidas como "declaratórias", de reconhecimento jurídico, e as de garantias são entendidas como "assecuratórias", limitadoras do poder para a defesa de direitos.
} 
ao trabalhador - dentre aqueles com regular condição de trabalho de remuneração variável - a devida percepção remuneratória de pelo menos um salário mínimo totalizado e não apenas reduzindo o salário mínimo a uma mera base de cálculo. Desse modo, uma regulamentação infraconstitucional que estabelece condição de trabalho com remuneração variável permissiva de seu total inferior ao salário mínimo implicará em restrição injustificável constitucionalmente.

Ora, por sua própria natureza e principalmente pela sua definição e sistemática previstas na CLT reformada no $\S 3^{\circ}$ do seu artigo 443 e nos $\S \S 1^{\circ}$ e $2^{\circ}$ e no inciso I do $\S 6^{\circ}$ do seu artigo 452 A, a dinâmica do trabalho intermitente consiste em uma remuneração extremamente variável ao trabalhador conforme a convocação/aceitação para a prestação de serviço e correspondente pagamento logo em seguida.

O reconhecimento da inconstitucionalidade das regras referentes à remuneração do contrato de trabalho intermitente proporcional ao período de prestação de serviço dadas pela Reforma Trabalhista dependerá da hipótese de sua aplicação no caso concreto. Para a hipótese de contrato em que trabalhador intermitente acumule mensalmente (referindo-se unicamente à remuneração a que se refere o inciso I do $\S 6^{\circ}$ do artigo 452-A da CLT reformada) uma percepção remuneratória igual ou superior ao salário mínimo, não há contrariedade constitucional das referidas regras trabalhistas. Por outro lado, na hipótese das regras trabalhistas permitirem o pagamento remuneratório acumulado no mês em um montante inferior ao salário mínimo, a regulamentação do contrato de trabalho intermitente estará violando a Constituição, esvaziando a efetividade do comando normativo e de seu parâmetro constitucional, podendo-se concluir que a legislação, em uma peculiar sistemática, instituiu a permissão de pagamento de remuneração trabalhista inferior ao salário mínimo.

Pelo princípio da "interpretação conforme à constituição", o intérprete constitucional é orientado no sentido de que "[...] se uma norma infraconstitucional, pelas peculiaridades da sua textura semântica, admite mais de um significado, sendo um deles coerente com a Constituição e os demais com ela incompatíveis, deve-se entender que aquele é o sentido próprio da regra em exame [...]." (BRANCO, 2019, p. 96) Ocorre que, no aspecto decisivo em controle de constitucionalidade, o emprego da interpretação conforme à Constituição por vezes sugere entendê-lo como equivalente ao da declaração de inconstitucionalidade sem redução de texto. Porém, apesar de, por vezes, tais técnicas apresentarem semelhanças nas suas práticas, elas são diferentes na sua técnica. Nesse sentido, segundo ensina Gilmar Ferreira Mendes (2019, p. 1487, grifo do autor):

\begin{abstract}
Ainda que se não possa negar a semelhança dessas categorias e a proximidade do resultado prático de sua utilização, é certo que, enquanto na interpretação conforme à Constituição se tem, dogmaticamente, a declaração de que uma lei é constitucional com a interpretação que lhe é conferida pelo órgão judicial, constata-se, na declaração de nulidade sem redução de texto, a expressa exclusão, por inconstitucionalidade, de determinadas hipóteses de aplicação do programa normativo sem que se produza alteração expressa do texto legal.
\end{abstract}

Assim, pela técnica de declaração de inconstitucionalidade sem redução de texto no controle de constitucionalidade, na decisão sobre lei ou ato normativo atacado, declara-se a sua inconstitucionalidade, porém parcialmente, mas não na textualidade de seu dispositivo e sim em um determinado âmbito de sua aplicação em que ela se coloca inconstitucional, ou seja, declarandoa inconstitucional apenas em uma específica hipótese de sua aplicação. Portanto, a respeito do disposto do $\S 3^{\circ}$ do artigo 443 e do inciso do $\S 6^{\circ}$ do artigo 452-A da CLT reformada, essas normas são parcialmente inconstitucionais, mas sem reduzir os seus textos normativos, pois o que as torna inconstitucionais é apenas uma hipótese de sua aplicação, que é a da situação de um trabalhador intermitente acumular uma percepção remuneratória mensal inferior ao salário mínimo, hipótese esta que esvazia a efetividade do direito encartado no inciso VII do artigo $7^{\circ}$ da Constituição. 


\subsubsection{O sentido de pagamento em dezembro para o direito de décimo terceiro salário}

Dispõe o inciso VIII do artigo $7^{\circ}$ da Constituição o direito fundamental trabalhista do "[...] décimo terceiro salário com base na remuneração integral ou no valor da aposentadoria[...]" (BRASIL, 1988, online). Para os trabalhadores, esse direito contempla dois aspectos: o décimo terceiro salário; e a remuneração integral como base de cálculo.

Referindo-se ao direito brasileiro, a origem dessa parcela se deu, segundo Delgado (2013, p. 771, grifo do autor), “[...] da normatividade autônoma trabalhista (costume ou regras coletivas negociadas), tendo provindo também de práticas concessivas unilaterais pelo empregador, despontando com nítida natureza jurídica de gratificação ( gratificação natalina)."

O caráter do que hoje se denomina como décimo terceiro salário é uma prática de gratificação aos trabalhadores motivada por um aspecto cultural ocorrente no mês de dezembro que é o período de evento natalino. De certo modo, isso pode ser notado na sua regulamentação, pois a Lei 4.090/1964 estabelece o mês de dezembro como o período de seu pagamento (artigo $1^{\circ}$ ), mantendo tal mês até mesmo em razão da divisão do seu pagamento em apenas dois períodos a título de adiantamento (Decreto 57.155/1965, artigo $3^{\circ}$ ). Essa concentração de pagamento em dezembro foi assim sistematicamente adaptada para assegurá-la semelhantemente aos trabalhadores com remuneração variável (Decreto 57.155/1965, artigo $2^{\circ}$ ), e até mesmo para os trabalhadores avulsos por meio de seu sistema de crédito em conta vinculada de cada trabalhador nessa condição (Lei 12.023/2009, artigo $7^{\circ}$ ). Portanto, a regulamentação mantém um tratamento isonômico entre essas espécies de trabalhadores sobre a concentração do pagamento desse direito no mês de dezembro, não reduzindo o sentido desse direito ao seu mero aspecto matemáticopecuniário, inclusive dando efetividade também ao inciso XXXIV do artigo $7^{\circ}$ da Constituição.

Diante dessa constatação, questiona-se: é constitucionalmente justificável discriminar legislativamente o trabalhador intermitente ao estabelecer-lhe o pagamento do décimo terceiro salário de maneira fragmentada? Além de violar o princípio constitucional da norma mais favorável ora referente ao caput do artigo $7^{\circ}$ da Constituição, o inciso III do $\S 6^{\circ}$ do artigo 452-A da CLT reformada está violando o princípio constitucional da isonomia (artigo $5^{\circ}$ caput da Constituição).

A igualdade encartada na Constituição "[...] mais do que um direito é um princípio, uma regra de ouro, que serve de diretriz interpretativa para as demais normas constitucionais." (BULOS, 2018, p. 560, grifo do autor) Por ocasião do Mandado de Injunção 58, o Supremo Tribunal Federal consignou uma linha de entendimento que distingue a igualdade entre "perante a lei" e igualdade "na lei", destacando-se que nesta espécie "[...] constitui exigência destinada ao legislador que, no processo de sua formação, nela não poderá incluir fatores de discriminação, responsáveis pela ruptura da ordem isonômica. [...].” (BRASIL. Supremo Tribunal Federal, 1991, 26)

A propósito, uma característica comum entre o trabalhador intermitente e o avulso é justamente a descontinuidade da prestação de serviços. Daí, na interpretação do inciso XXXIV do artigo $7^{\circ}$ da Constituição, como condição de sua aplicabilidade, segundo explica Bulos (2018, p. 844) "[...] pressupõe o prévio exame da compatibilidade, ou não, do direito previsto em lei para o trabalho contínuo do empregado e a natureza descontínua do serviço prestado pelo avulso." Ora, para os trabalhadores avulsos a compatibilização da concentração em dezembro para o pagamento do décimo terceiro salário se revela na sistemática de sua regulamentação (Lei 12.023/2009, artigo $7^{\circ}$ ) Ademais, como mencionado acima, essa concentração em dezembro também foi adequada para os empregados com remuneração variável.

Logo, a discriminação dada pela Reforma Trabalhista ao trabalhador intermitente no tocante à fragmentação do pagamento do décimo terceiro salário caracteriza-se como violação ao princípio constitucional da isonomia esvaziando-o na sua efetividade para a presente situação comentada, tornando, portanto, inconstitucional a regra do inciso III do $\S 6^{\circ}$ do artigo $452-\mathrm{A}$ da 
CLT reformada. Ademais, esta regra trabalhista também se caracteriza como uma restrição constitucionalmente injustificável do princípio da norma mais favorável ao trabalhador constante no caput do artigo $7^{\circ}$ da Constituição.

A despeito do posicionamento assumido acima, não se pode olvidar que a Reforma Trabalhista ampliou significativamente o alcance da negociação coletiva (art. 611-A da CLT reformada), restringindo, no entanto, a possibilidade de a negociação coletiva prevalecer sobre a lei nas hipóteses expressa e taxativamente indicadas no art. 611-B da CLT reformada, entre as quais está previsto ser objeto ilícito de convenção ou de acordo coletivo de trabalho a supressão ou a redução do valor nominal do décimo terceiro salário. Veja-se que o legislador restringiu a negociação coletiva apenas ao valor nominal do décimo terceiro salário, não vedando, porém, a mesma em relação à definição da época de pagamento que, portanto, poderá ser negociada de forma distinta à prevista na Lei 4.090/1964 e no Decreto 57.155/1965. Tal previsão parece, portanto, minimizar a violação ao princípio da isonomia pela previsão de pagamento ao trabalhador intermitente do décimo terceiro salário proporcional quando do término de cada período trabalhado.

\subsubsection{O sentido de direito de fruição remunerada das férias}

Tal como ocorre, como regra, em relação ao período do pagamento do décimo terceiro salário, conforme explicado no subitem anterior, a dissonância discriminatória do principio constitucional da igualdade na regulamentação dos trabalhadores intermitentes também se caracteriza pelo mesmo raciocínio com relação ao período para o pagamento da remuneração do direito de férias. As normas trabalhistas estabelecem o seu pagamento, para os empregados permanentes, coincidente com o período do início da concessão da fruição (na forma do artigo 145 da CLT), e para os trabalhadores avulsos com adaptação pelo sistema de crédito em conta vinculada (na forma do artigo $7^{\circ}$ da Lei 12.023/2009), mas a Reforma Trabalhista discriminou o trabalhador intermitente ao fragmentar o seu pagamento juntamente com o da remuneração, fazendo, com isso, que a sua fruição das férias fique amplamente separada da correspondente remuneração.

Mas, além dessa contrariedade, a regra de pagamento das férias ao trabalhador intermitente também entra em confronto com o próprio sentido do direito de férias elevado à qualidade de direito fundamental. Dispõe o inciso XVII do artigo $7^{\circ}$ da Constituição como um direito fundamental trabalhista o "[...] gozo de férias anuais remuneradas com, pelo menos, um terço a mais do que o salário normal[...]" (BRASIL, 1988, online).

No texto dessa norma constitucional, segundo explica Amauri Mascaro Nascimento (2015, p. 824, grifo do autor), “[...] está a estrutura tríplice da figura jurídica das férias e os seus três princípios, o princípio da fruição, o princípio da anualidade e o princípio da sobrerremuneração." Explica ainda que "[s]e as férias não são efetivamente gozadas, para que assim seja possível o descanso do trabalhador, e se este não dispuser de recursos econômicos para enfrentar os gastos com o lazer, as férias não atingirão os seus normais objetivos. [...]." (NASCIMENTO, 2015, p. 825)

Assim, compreende-se que o direito fundamental de férias possui um sentido indissociável de fruição e de remuneração, a ser paga quando iniciar a sua concessão, ou seja, o direito do direito de fruição de férias anuais remuneradas significa o direito de fruição remunerada de férias anuais, ainda que a fruição seja fracionada em dois períodos na forma do $\S 1^{\circ}$ do artigo 134 da CLT reformada, já que o primeiro período de sua fruição coincidirá próximo e substancialmente com o da remuneração (artigo 145).

Daí, comparando essa compreensão do direito fundamental de fruição remunerada de férias com o que dispõe a regra de pagamento desse instituto jurídico dado pela Reforma Trabalhista ao empregado intermitente (pagamento fragmentado logo após cada término da prestação do serviço convocado, restando a fruição dissociada da remuneração), verifica-se que o 
inciso II do $\S 6^{\circ}$ do artigo 452-A da CLT reformada esvazia a efetividade do inciso VII do artigo $7^{\circ}$ da Constituição, tratando-se de, portanto, de uma inconstitucionalidade.

\section{CONCLUSÃO}

O trabalho intermitente, independentemente de elogio ou crítica, é uma tendência da atividade econômica contemporânea, que mais cedo ou mais tarde o direito brasileiro renderia inevitavelmente a regulamentar, pois o que pressiona para essa tendência é a própria realidade estrutural do capitalismo contemporâneo, que se desenvolve sob demandas altamente flexíveis no mercado.

Contudo, a regulamentação do trabalho intermitente na forma dada pela Reforma Trabalhista pode servir de solução para o problema da informalidade no trabalho (pelo menos é o que se propagou quando da promulgação da Lei n. 13.467/2017 e é o que se espera), mas não resolve o problema da precarização, pelo contrário, contribui para estender agressivamente esse fenômeno enquanto mantiver o critério generalizado de admissão do trabalho intermitente independente de atividade da empresa ou do trabalhador, e principalmente pela forma como o elemento descontinuidade foi sistematizado para esta modalidade contratual de trabalho.

O elemento descontinuidade na definição jurídica do contrato de trabalho intermitente na forma dada pela Reforma Trabalhista possibilita consequências devastadoras no mundo do trabalho, a ponto de pôr em risco a própria viabilidade do emprego permanente, tornando-a uma modalidade em desuso, prejudicando assim uma série de proteções jurídicas aos trabalhadores (por exemplo, em uma empresa que contenha somente trabalhadores intermitentes, para reduzir gastos com folha de pagamento basta apenas reduzir as convocações para prestação de serviços, ou seja, uma maneira indireta de redutibilidade de salários por ato unilateral da empresa).

De qualquer modo, a Constituição não proíbe a regulamentação do trabalho intermitente em si, sendo que o que ela veda são alguns aspectos jurídicos contidos na sua regulamentação dada pela Reforma Trabalhista, destacando-se algumas questões referentes à forma de pagamento fragmentado da contraprestação do serviço prestado e efetuado logo após a sua prestação, regras estas que são confrontadas com específicos direitos fundamentais, e estes por sua vez interpretados juntamente com sob o sentido orientado pelo princípio da norma mais favorável ao trabalhador agregadamente ao da dignidade da pessoa humana, do valor social do trabalho e da valorização do trabalho humano.

Nesse sentido, pela efetividade da garantia fundamental trabalhista do salário mínimo para os trabalhadores com percepção de remuneração variável, as regras que liberam a prestação do trabalho intermitente são constitucionalmente admitidas somente na hipótese de conferir ao trabalhador nessa condição o acúmulo mensal de remuneração igual ou superior ao montante de um salário mínimo.

A regra do pagamento fragmentado do décimo terceiro salário ao trabalhador intermitente logo após cada prestação de serviços ao invés de sua concentração em expressivo montante no mês de dezembro (embora, como visto, isto possa ser estabelecido por meio de negociação coletiva válida, na forma prevista no art. 611-B, CLT) constitui-se em regulamentação discriminatória e prejudicial a essa espécie de trabalhador, pois o legislador, pelas suas regras instituídas pela Reforma Trabalhista, não compatibilizou a efetividade do pagamento desse direito fundamental tal como foi feito aos empregados com remuneração variável e aos trabalhadores avulsos.

A concessão da fruição do direito de férias sem a correspondente remuneração concentrada para tanto esvazia o objetivo do direito fundamental de férias anuais remuneradas. Logo, a regra do pagamento fragmentado das férias ao trabalhador intermitente logo após a prestação de serviços o prejudica tanto pela inviabilização da devida fruição remunerada do direito de férias, fazendo com que o período de seu descanso sem a concentração de sua correspondente remuneração consubstancia-se num estado de inatividade compulsória.

Revista de Direito Brasileira | Florianópolis, SC | v. 24 | n. 9 | p.293-310 | Set./Dez. 2019 
Portanto, sem significar uma crítica indiscriminada ao trabalho intermitente e a essa modalidade de contratação, o presente trabalho pretendeu demonstrar, no entanto, que a forma de regulamentação do mesmo não foi das melhores e traz em si inúmeras afrontas à Constituição Federal que necessitam ser enfrentadas pelos Tribunais, visando a manutenção de direitos fundamentais dos trabalhadores.

\section{REFERÊNCIAS}

ALEXY, Robert. Teoria dos direitos fundamentais. 2. ed. 5. tiragem. São Paulo: Malheiros, 2017.

ALVES, Giovanni. Dimensões da reestruturação produtiva: ensaios de sociologia do trabalho. 2. ed. Londrina: Praxis; Bauru: Canal 6, 2007. Disponível em: 〈www.giovannialves.org/DRP.pdf〉. Acesso em: 26 jun. 2019.

ANTUNES, Ricardo. A nova morfologia do trabalho e duas principais tendências[:] informalidade, infroproletariado, (i)materialidade e valor. In: ANTUNES, Ricardo. (org.)

Riqueza e miséria do trabalho no Brasil II. 1. ed. São Paulo: Boitempo, 2013. p. 13-27.

. O privilégio da servidão: o novo proletariado de serviços na era digital. 1. ed. São Paulo: Boitempo, 2018.

ANTUNES, Ricardo; DRUCK, Graça. A terceirização sem limites: a precarização do trabalho como regra. O Social em Questão, ano 18, n. 34, Rio de Janeiro, 2015, p. 19-40. Disponível em: <http://osocialemquestao.ser.puc-rio.br/media/OSQ_34_1_Antunes_Druck.pdf>. Acesso em: 12 jun. 2019.

BARBOSA, Rui. República: teoria e prática: textos doutrinários sobre direitos humanos e políticos consagrados na Primeira Constituição Republicana. Petrópolis: Vozes; Brasília, DF: Câmara dos Deputados, 1978.

BRANCO, Paulo Gustavo Gonet. Noções introdutórias. In: MENDES, Gilmar Ferreira; BRANCO, Paulo Gustavo Gonet. Curso de direito constitucional. 14. ed. São Paulo: Saraiva, 2019. (Série IDP). Ebook. p. 37-100.

BRANDÃO, Cláudio Mascarenhas. Art. $1^{\circ}$, IV. In: CANOTILHO, José Joaquim Gomes et al. Comentários à Constituição do Brasil. 2. ed. São Paulo: Saraiva, 2018. (Série IDP). Ebook. p. 129-135.

BRASIL. Constituição (1988). Constituição da República Federativa do Brasil: versão atualizada até a Emenda n. 99/2017. Disponível em:

<http://www.planalto.gov.br/ccivil_03/Constituicao/Constituicao.htm>. Acesso em: 19 jun. 2019.

Decreto-Lei N. ${ }^{\circ}$ 5.452, de $1^{\circ}$ de Maio de 1943. Aprova a Consolidação das Leis do Trabalho. 1943. Disponível em: <http://www.planalto.gov.br/ccivil_03/decretolei/Del5452.htm>. Acesso em: 6 jun. 2019.

. Supremo Tribunal Federal. Mandado de Injunção [58]. Airton de Oliveira e outros, Presidente da República. Relator Ministro Carlos Velloso. Relator para o Acórdão Ministro Celso de Mello. Brasília, DF, 19 de abril de 1991. p. 26-39. Disponível em:

<http://redir.stf.jus.br/paginadorpub/paginador.jsp?docTP=AC\&docID=81737>. Acesso em: 27 
jun. 2019.

BULOS, Uadi Lammêgo. Curso de direito constitucional. 11. ed. São Paulo: Saraiva, 2018. Ebook.

CASTEL, Robert. As metamorfoses da questão social: uma crônica do salário. 10. ed. Petrópolis: Vozes, 2012.

CORIAT, Benjamin. Pensar pelo avesso: o modelo japonês de trabalho e organização. Rio de Janeiro: Revan: UFRJ, 1994.

DELGADO, Mauricio Godinho. Curso de direito do trabalho. 12. ed. São Paulo: LTr, 2013. Ebook. . Princípios de direito individual e coletivo do trabalho. 3. ed. São Paulo: LTr, 2010.

DELGADO, Mauricio Godinho; DELGADO, Gabriela Neves. A reforma trabalhista no Brasil: com os comentários à Lei n. 13.467/2017. São Paulo: LTr, 2017.

GOUNET, Thomas. Fordismo e toyotismo na civilização do automóvel. São Paulo: Boitempo, 1999.

FORD, Henry. Os princípios da prosperidade. Rio de Janeiro: Brand, 1954.

GRAU, Eros Roberto. Art. 170. In: CANOTILHO, José Joaquim Gomes et al. Comentários à Constituição do Brasil. 2. ed. São Paulo: Saraiva, 2018. (Série IDP). Ebook. p. 1877-1886.

HARVEY, David. Condição pós-moderna: uma pesquisa sobre as origens da mudança cultural. 25. ed. São Paulo: Edições Loyola, 2014.

LARAIA, Maria Ivone Fortunato. Direito fundamental ao trabalho digno e o contrato de trabalho intermitente. 2018. 249 f. Tese (Doutorado em Direito) -- Pontifícia Universidade Católica de São Paulo, São Paulo, 2018. Disponível em:

<https://tede2.pucsp.br/bitstream/handle/21767/2/Maria\%20Ivone\%20Fortunato\%20Laraia.pdf>. Acesso em: 17 jun. 2019.

MALLET, Estêvão; FAVA, Marcos. Art. $7^{\circ}$, XV. In: CANOTILHO, José Joaquim Gomes et al. Comentários à Constituição do Brasil. 2. ed. São Paulo: Saraiva, 2018. (Série IDP). Ebook. p. 627-629.

MENDES, Gilmar Ferreira. Controle de constitucionalidade. In: MENDES, Gilmar Ferreira; BRANCO, Paulo Gustavo Gonet. Curso de direito constitucional. 14. ed. São Paulo: Saraiva, 2019. (Série IDP). Ebook. p. 1169-1562.

NASCIMENTO, Amauri Mascaro. Curso de direito do trabalho: história e teoria geral do direito do trabalho: relações individuais e coletivas do trabalho. 29. ed. 3. tiragem. São Paulo: Saraiva, 2015. Ebook.

ORGANIZACIÓN INTERNACIONAL DEL TRABAJO. El empleo atípico en el mundo: retos y perspectivas. Presentación resumida del informe. Genebra: OIT, 2016. Disponível em: 
<https://www.ilo.org/wcmsp5/groups/public/---dgreports/---dcomm/---

publ/documents/publication/wcms_534518.pdf>. Acesso em: 10 jul. 2019.

OHNO, Taiichi. O sistema Toyota de produção: além da produção em larga escala. Reimpr. 2015. Porto Alegre: Bookman, 2015.

PINTO, Geraldo Augusto. A organização do trabalho no século XX: taylorismo, fordismo e toyotismo. 3. ed. 2. reimpressão. São Paulo: Expressão Popular, 2016.

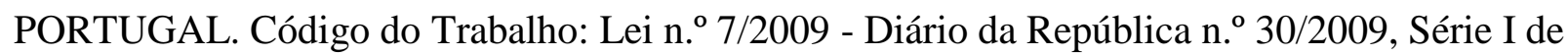
2009-02-12. 2009. Disponível em: <https://dre.pt/web/guest/legislacao-consolidada//lc/114799007/201906172105/exportPdf/normal/1/cacheLevelPage?_LegislacaoConsolidada_W AR_drefrontofficeportlet_rp=indice>. Acesso em 17 jun. 2019.

RODRIGUEZ, Américo Plá. Princípios de direito do trabalho. 3. ed. 2. tiragem. São Paulo: LTr, 2002.

ROMAR, Carla Teresa Martins. Direito do trabalho esquematizado. 4. ed. São Paulo: Saraiva, 2017. Ebook.

SARLET, Ingo Wolfgang. A eficácia dos direitos fundamentais: uma teoria geral dos direitos fundamentais na perspectiva constitucional. 11. ed. Porto Alegre: Livraria do Advogado Editora, 2012.

SILVA, José Afonso da. Aplicabilidade das normas constitucionais. 8. ed. 2. tiragem. São Paulo: Malheiros Editores, 2015.

SILVA, Virgílio Afonso da. Direitos fundamentais: conteúdo essencial, restrições e eficácia. 2. ed. 2. tiragem. São Paulo: Malheiros Editores, 2011.

TAYLOR, Frederick Winslow. Princípios de administração científica. 8. ed. São Paulo: Atlas, 1995. 